\title{
Evidence Against Either a Premature Stop Codon or the Absence of Obese Gene mRNA in Human Obesity
}

\author{
Robert V. Considine, ${ }^{*}$ Eileen L. Considine, ${ }^{\ddagger}$ Charlene J. Williams, ${ }^{\ddagger}$ Mark R. Nyce, ${ }^{\star}$ Susan A. Magosin, ${ }^{*}$ Thomas L. Bauer, ${ }^{\$}$ \\ Emest L. Rosato, $\$$ James Colberg, $\$$ and Jose F. Caro* \\ * Division of Endocrinology and Metabolism, Department of Medicine, ${ }^{\ddagger}$ Department of Biochemistry and Molecular Biology, and \\ ${ }^{\S}$ Department of Surgery, Jefferson Medical College of Thomas Jefferson University, Philadelphia, Pennsylvania 19107
}

\begin{abstract}
Obese $(o b)$ gene expression in abdominal subcutaneous adipocytes from lean and obese humans was examined. The full coding region of the $o b$ gene was isolated from a human adipocyte cDNA library. Translation of the insert confirmed the reported amino acid sequence. There was no difference in the sequence of an reverse transcription PCR product of the coding region from five lean and five obese subjects. The nonsense mutation in the $o b$ mouse which results in the conversion of arginine 105 to a stop codon was not present in human obesity. In all 10 human cDNAs, arginine 105 was encoded by CGG, consequently two nucleotide substitutions would be required to result in a stop codon. To compare the amount of $o b$ gene expression in lean and obese individuals, radiolabed primer was used in the PCR reaction with $\beta$ actin as a control. There was $72 \%$ more $o b$ gene expression $(P<0.01)$ in eight obese subjects (body mass index, BMI $=42.8 \pm 2.7$ ) compared to eight lean controls (BMI $=22.4 \pm 0.8$ ). Regression analysis indicated a positive correlation between BMI and the amount of $o b$ message $(P$ $<0.005)$. There was no difference in the amount of $\beta$-actin expression in the two groups. These results provide evidence that $o b$ gene expression is increased in human obesity; furthermore, the mutations present in the mouse $o b$ gene were not detected in the human mRNA population. (J. Clin. Invest. 1995. 95:2986-2988.) Key words: obese gene $\cdot$ reverse transcription PCR • human adipocyte
\end{abstract}

\section{Introduction}

The genetic and/or environmental influences that contribute to the development of human obesity are poorly understood (1$5)$. Friedman and coworkers have recently cloned the obese $(o b)^{1}$ gene in mice and also found its human homologue (6).

Address correspondence to Robert V. Considine, Thomas Jefferson University, 1025 Walnut Street, 813 College Building, Philadelphia, PA 19107-5083.Phone: 215-955-8791; FAX: 215-955-2318.

Received for publication 23 January 1995 and in revised form 1 March 1995.

1. Abbreviations used in this paper: BMI, body mass index; ob, obese; RT-PCR, reverse transcription PCR.

J. Clin. Invest.

(C) The American Society for Clinical Investigation, Inc.

0021-9738/95/06/2986/03 $\$ 2.00$

Volume 95, June 1995, 2986-2988
These investigators postulate that the product of the $o b$ gene, which is expressed exclusively in the adipocyte, is a satiety factor that controls food intake by signaling the hypothalamus when the store of energy is sufficient. Previous studies (transfusion and parabiosis) have predicted the existance of such a circulating factor (reviewed in references 7,8 ). In the $o b / o b$ mouse, two separate mutations in the $o b$ gene result in either a premature stop codon or the total absence of $o b$ mRNA. Without this signaling protein, the mouse overeats resulting in the obese phenotype.

The present study provides evidence that the mutations present in the mouse $o b$ gene are not present in obese humans.

\section{Methods}

Subjects. Eight healthy lean (five female/three male, body mass index (BMI) $22.4 \pm 0.8 \mathrm{~kg} / \mathrm{m}^{2}$, body fat $18.2 \pm 1.07 \%$, age $26 \pm 1.3 \mathrm{yr}$ ) and eight healthy obese (five female/three male, BMI $42.8 \pm 2.7 \mathrm{~kg} / \mathrm{m}^{2}$, body fat $44.8 \pm 2.8 \%$, age $41.6 \pm 4.1 \mathrm{yr}$ ) individuals provided abdominal subcutaneous adipose tissue biopsies following informed written consent (9). None of the individuals were taking medications or had any evidence of metabolic disease other than obesity. All biopsies were performed in the morning after an overnight fast. Tissue was transported to the laboratory in saline and immediately digested by collagenase. This protocol has been approved by the Institutional Review Board at Thomas Jefferson University, Philadelphia, PA.

Reverse transcription PCR ( $R T-P C R)$. Adipocytes were isolated by collagenase digestion of outpatient subcutaneous adipose tissue biopsies as previously described (9). Total RNA was obtained by guanidinium thiocyanate-phenol-chloroform extraction (10). First strand cDNA was synthesized from $1 \mu \mathrm{g}$ of total RNA using random hexamers as described in the GeneAmp RNA PCR kit (Perkin-Elmer Corp., Branchburg, NJ). As only the predicted amino acid sequence was available for the human $o b$ gene product (6) the following degenerate primers were synthesized: sense; 5'-CA(T/C)TGGGG(A/T/C/G) AC (A/T/C/G)CT(A/T/C/ G)TG(T/C)GG-3' and antisense; 5'-TG(A/G)CA(A/G)CT(T/ C)TT(A/T/C/G)GA(A/G)AA(A/T/C/G)GC-3'. These primers enclose the coding sequence corresponding to amino acids 2-118 ( $\sim 350 \mathrm{bp}$ ) of the human $o b$ gene product. PCR (11) was performed using $50 \mathrm{pmol}$ final concentration of the primers for 35 cycles using a 1-min denaturation step at $94^{\circ} \mathrm{C}$, a 1 -min annealing step at $50^{\circ} \mathrm{C}$, and a 1 -min extension step at $72^{\circ} \mathrm{C}$. An additional 7 -min extension step at $72^{\circ} \mathrm{C}$ was added after the 35 cycles. PCR reactions were performed in a thermocycler (model 480; Perkin-Elmer Corp. A single major PCR product was obtained under these conditions for one lean and one obese subject. The product from both the lean and obese was cloned with the Invitrogen T/A cloning kit (San Diego, CA) and subjected to automated sequencing using the M13 $(-20)$ reverse primer.

To determine the amount of $o b$ gene expression in lean and obese individuals, first strand cDNA was generated as described above. The reaction was then split equally into two separate tubes for the PCR reaction. The first tube was used to amplify $\sim 350$ base pairs of the $o b$ 


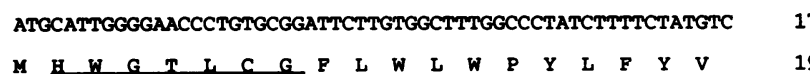

CAAGCTGTGCCCATCCAAAAAGTCCAAGATGACACCAAAACCCTCATCAAGACAATT

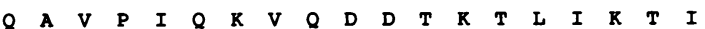

GTCACCAGGATCAATGACATTTCACACACGCAGTCAGTCTCCTCCAAACAGAAAGTC

$\begin{array}{llllllllllllllllllll}V & T & R & I & N & D & I & S & H & T & Q & S & V & S & S & K & Q & K & V\end{array}$

ACCGGTTTGGACTTCATTCCTGGGCTCCACCCCATCCTGACCTTATCCAAGATGGAC

$\begin{array}{llllllllllllllllllll} & T & G & \text { L } & D & F & I & P & G & \text { L } & \text { H } & \text { P } & \text { I } & \text { L } & \text { T } & \text { L } & S & K & \text { M } & D\end{array}$

CAGACACTGGCAGTCTACCAACAGATCCTCACCAGTATGCCTTCCAGAAACGTGATC

$\begin{array}{llllllllllllllllllll}Q & \text { T } & \text { L } & \text { A } & \text { V } & \text { Y } & \text { Q } & \text { Q } & \text { I } & \text { L } & \text { T } & \text { S } & \text { M } & \text { P } & \text { S } & R & \text { N } & \text { V } & \text { I }\end{array}$

CAAATATCCAACGACCTGGAGAACCTCCGGGATCTTCTTCACGTGCTGGCCTTCTCT

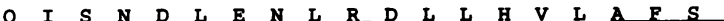

AAGAGCTGCCACTTGCCCTGGGCCAGTGGCCTGGAGACCTTGGACAGCCTGGGGGGT

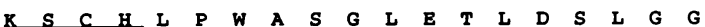

GTCCTGGAAGCTTCAGGCTACTCCACAGAGGTGGTGGCCCTGAGCAGGCTGCAGGGG

571

$\begin{array}{llllllllllllllllllll}V & \text { L } & \text { E } & \text { A } & \text { S } & G & \text { Y } & \text { S } & \text { T } & \text { E } & \text { V } & \text { V } & \text { A } & \text { L } & \text { S } & R & \text { L } & Q & G\end{array}$

TCTCTGCAGGACATGCTGTGGCAGCTGGACCTCAGCCCTGGGTGCTGA

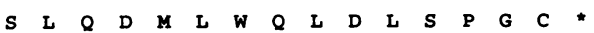

Figure 1. Sequence of the entire coding region of the human $o b$ gene. The sequence was obtained from a human adipocyte cDNA library and codes for 167 amino acids (numbering based on that in reference 6). The primer sequences used for the analysis in Fig. 3 are underlined as well as the codon for arginine 105.

gene cDNA corresponding to amino acids $2-118$. The second tube was used to generate a 220-bp fragment of the $\beta$-actin cDNA using primers available from Clontech (Palo Alto, CA). The downstream primer in each reaction was radiolabed using $\mathrm{T}_{\mathbf{4}}$ polynucleotide kinase (Promega Corp., Madison, WI) and $\gamma-\left[{ }^{32} \mathrm{P}\right]$ ATP (Amersham Corp., Arlington Heights, IL). The PCR conditions were as described above with a final primer concentration of $10 \mathrm{pmol}$. The PCR product was resolved on a $2 \%$ agarose gel, the band excised, and the radioactivity incorporated measured by Cerenkov counting. To insure that the comparison of lean to obese was done in the linear amplification range, samples were taken after 15,25 , and 35 cycles. The reaction was linear over this range for both the lean $(r=0.98)$ and obese $(r=1.0)$ (the data in Fig. 3 is after 25 cycles of amplification). There was no difference in the amount of $\beta$-actin between lean $(19,422 \pm 1,276 \mathrm{cpm} ; n=8)$ and obese $(20,109 \pm 1,817 \mathrm{cpm} ; n=8)$. The contribution of genomic DNA contamination to the final PCR product was determined by doing the reverse transcription step in the absence of the reverse transcriptase. There was no difference between lean and obese in the number of counts $(25 \pm 5 \%)$ attributable to DNA contamination after 25 cycles of PCR reaction.

cDNA library screen. The full-length coding sequence of the human $o b$ gene was isolated from an adipose tissue cDNA library (Clontech). The library was probed with the PCR product corresponding to amino acids 2-118 described above. Inserts were prepared by PCR amplification using primers adjacent to the cloning site of $\lambda$ gt 11 . The insert DNA was sequenced by automated sequencing protocols.

Sequence analysis. All DNA was subjected to automated sequencing protocols in the Molecular biology core facility at Thomas Jefferson University, Philadelphia, PA. Analysis of human cDNA was done in

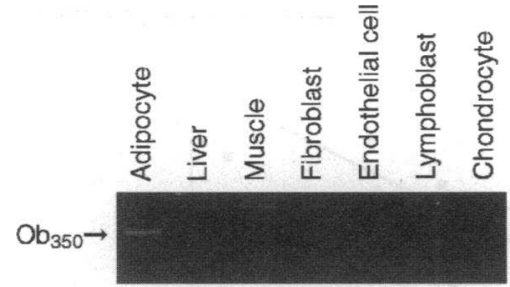

Figure 2. Expression of $o b$ gene in human tissue. RT-PCR using $1 \mu \mathrm{g}$ of total or mRNA from the various tissues was performed as described. The $o b$ gene fragment was only detected in the isolated adipocyte. $\beta$-actin expression was detected in all tissues studied.

two parts. The first PCR product contained $\sim 350$ bp corresponding to amino acids 1-118. The second PCR product contained the last $\sim 150$ bp corresponding to amino acids 105 through the stop codon. The two PCR products were obtained for five lean and five obese individuals and directly sequenced. Both the sense and antisense PCR primers were used as sequencing primers.

Miscellaneous. All data are expressed as the mean \pm SEM. Statistical analyses were performed using the Statview software package for Macintosh (Abacus Concepts, Inc., Berkeley, CA). $P<0.05$ in one-way ANOVA comparisons was taken as statistically significant.

\section{Results}

Sequence of the human ob gene product. Using degenerate primers based on the reported human amino acid sequence of the $o b$ gene product, we reverse transcribed and amplified a 350-bp segment of $o b$ gene mRNA from adipose tissue. We were equally successful in amplification of this product with total RNA from either lean or obese subjects. The translated sequence of the PCR product encoded 116 complete amino acids (2-118), including those in the primers. The 350-bp sequence was then used to probe a human adipocyte cDNA library. A positive clone was isolated and the insert sequenced to yield the full coding region of the $o b$ gene (Fig. 1). The translated sequence codes for a protein of 167 amino acids which are identical to those previously reported for humans (6).

The $o b$ gene mRNA from five lean and five obese individuals was sequenced for possible mutations as observed in the $o b / o b$ mouse. The sequence derived from the lean and obese cDNA were identical. It is important to note that, in contrast to the mouse codon for arginine 105 (CGA), human arginine 105 is encoded by CGG. It is, therefore, much less likely that the human codon could mutate to a stop codon. The cDNA derived from all 10 subjects studied contained the complete codon for glutamine 49.

Specificity of ob gene expression. Using primers that enclose amino acids $2-118$, several human tissues were examined for the expression of the $o b$ gene. As shown in Fig. 2, $o b$ gene expression was limited in humans to the adipocyte. $\beta$-actin mRNA, run as a positive control through the RT-PCR reaction, was expressed in all tissues studied.

Expression of $o b$ gene in lean and obese individuals. $O b$ gene expression in lean versus obese individuals was examined by measuring the incorporation of radiolabeled downstream primer into the 350-bp PCR product. As a control, a radiolabeled 220 -bp fragment of the mRNA for $\beta$-actin was generated from the same reverse transcription reaction for each individual. 


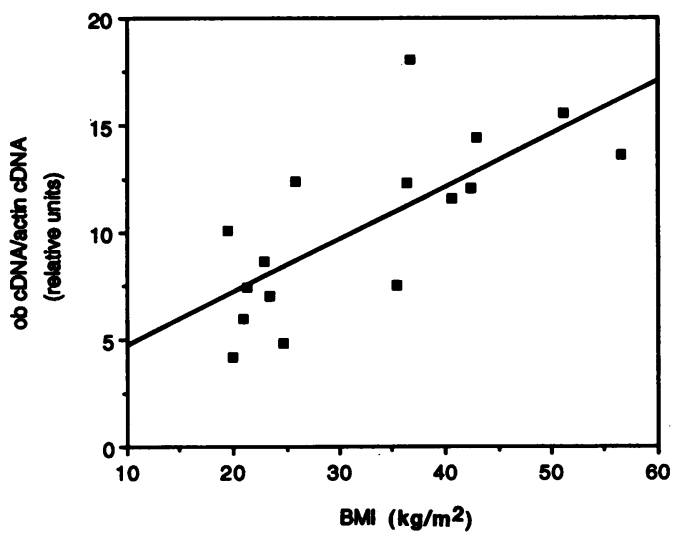

Figure 3. Correlation of $o b$ gene expression with BMI. The relative amount of $o b$ gene expression in abdominal subcutaneous adipocytes was determined by RT-PCR using radiolabeled primers after 25 cycles of amplification as described. The correlation coefficient is statistically significant $(P<0.005)$

There was no difference in the amount of $\beta$-actin mRNA between the lean and obese groups. However, as shown in Fig. 3 , there was a positive correlation between $o b$ gene expression and the BMI of the individual studied. Linear regression analysis indicated that the correlation was highly significant $(P$ $<0.005$ ). Overall, there was $72 \%$ more $o b$ gene expression in the obese subjects $(13.1 \pm 1.0$ relative units; $n=8)$ compared to the lean $(7.6 \pm 1.0$ relative units; $n=8)$ when normalized to the amount of message for $\beta$-actin $(P<0.01$; one-way ANOVA).

\section{Discussion}

The amino acid sequence of the human homologue to the mouse $o b$ gene product has recently been published (6). Based on this information we have begun a preliminary examination into the expression and possible role of the $o b$ gene product in human obesity. To this end using RT-PCR we have demonstrated that $o b$ gene expression in humans appears to be limited to the adipocyte as observed in mice. Two mutations in the mouse $o b$ gene were found which were hypothesized to contribute to the development of obesity: either no mRNA production or the synthesis of a flawed message coding for an incomplete protein. Although a subset of obese humans may yet be found that lack $o b$ mRNA, this was not the case in our study population which included a range of individuals some of which were morbidly obese. With regard to the second mutation in the mouse, sequencing of five obese individuals failed to detect a stop codon at arginine 105 in the mRNA population. Although genomic DNA must be screened to rule out the possibility that only the normal $o b$ allele is represented in the mRNA population, it is less likely that arginine 105 would mutate to a stop codon in humans than in mice. In all 10 human cDNAs sequenced to date, arginine 105 was encoded by CGG. Consequently, two nucleotide substitutions would be required to result in a stop codon. It should be noted that although the two characterized defects in the mouse mRNA were not detected in the 10 human subjects studied, this does not rule out the possibility that these or other deleterious mutations could occur in a subpopulation of obese individuals.

Using RT-PCR we have demonstrated that there is significantly more $o b$ gene expression in the subcutaneous adipose tissue of obese individuals when compared to lean subjects. Assuming that the $o b$ gene product does indeed code for a satiety factor, this observation suggests that the adipocyte is functioning normally and that the defect in human obesity lies elsewhere. One possibility is that the receptor for the $o b$ protein is blocked or defective. A second possibility is that the protein is degraded and never reaches its target. A third possibility is that the $o b$ gene product signals for the release of another, as yet unidentified hormone which is defective. Each of these possibilities is predicated on the assumption that the $o b$ gene actually codes for a satiety factor and not some other protein. Positive proof of this awaits the isolation of the protein in the blood and the demonstration that it does indeed influence appetite.

In summary, $o b$ gene expression in humans, as in mice, appears to be limited to the adipocyte. However, unlike the mouse model, no lack of message or flawed message was detected in the human subjects. Additionally, $o b$ gene expression was highly correlated with BMI. Further work is necessary to elucidate the exact role of the $o b$ gene in human obesity.

\section{Acknowledgments}

The authors sincerely thank John T. Flynn for the human endothelial cell mRNA.

This work was supported in part by grant R01 DK45592 and fellowship 1F32 DK08888 from the National Institutes of Health.

\section{References}

1. Bray, G. A. 1993. The nutrient balance hypothesis: peptides, sympathetic activity, and food intake. Ann. NY Acad. Sci. 676:223-241.

2. Stunkard, A. J. 1991. Genetic contributions to human obesity. Res. Publ. Assoc. Res. Nerv. Ment. Dis. 69:205-218.

3. Greeno, C. G., and R. R. Wing. 1994. Stress-induced eating. Psychol. Bull. 115:444-464.

4. Friedman, J. M., and R. L. Leibel. 1992. Tackling a weighty problem. Cell. 69:217-220.

5. Ailhaud, G., P. Grimaldi, and R. Negrel. 1992. A molecular view of adipose tissue. Int. J. Obes. 16:S17-S21.

6. Zhang, Y., R. Proenca, M. Maffei, M. Barone, L. Leopold, and J. M. Friedman. 1994. Positional cloning of the mouse obese gene and its human homologue. Nature (Lond.). 372:425-432.

7. Weigle, D. S. 1994. Appetite and the regulation of body composition. FASEB (Fed. Am. Soc. Exp. Biol.) J. 8:302-310.

8. Coleman, D. L. 1978. Obese and diabetes: two mutant genes causing diabetes-obesity syndromes in mice. Diabetologia. 14:141-148.

9. Kolaczynski, J. W., L. M. Morales, J. H. Moore, Jr., R. V. Considine, Z. Pietrzkowski, P. F. Noto, J. Colberg, and J. F. Caro. 1994. A new technique for biopsy of human abdominal fat under local anaesthesia with Lidocaine. Int. J. Obes. 18:161-166.

10. Chomczynski, P., and N. Sacchi. 1987. Single step method of RNA isolation by acid guanidinium thiocyanate-phenol-chloroform extracts. Anal. Biochem. 162:156-159.

11. Saiki, R. K., S. Scharf, F. Faloona, K. B. Mullis, G. T. Horn, H. A. Erlich and $\mathrm{N}$. Arnheim. 1985. Enzymatic amplification of beta-globin genomic sequences and restriction site analysis for diagnosis of sickle cell anemia. Science (Wash. DC). 230:1350-1354. 